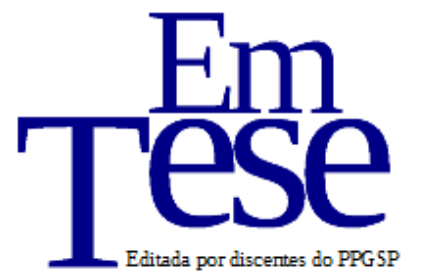

\title{
Fotografia como recurso didático no ensino de sociologia
}

\section{Cristiano das Neves Bodart ${ }^{1}$}

\section{Introdução}

É sabido que a imagem fotográfica captura aspectos importantes das relações sociais as quais retratam (BOURDIEU, 1990; MARTINS, 2014), assim como sabe-se que sua presença é marcante no cotidiano contemporâneo, seja pela facilidade de acesso a uma máquina fotográfica (que está embutida em quase todos os celulares, por exemplo), seja pela centralidade que a imagem vem adquirindo na contemporaneidade. Se aproveitando desses dois aspectos, propõe-se discutir a potencialidade do uso da fotografia como recurso didático, especificamente na busca por ensinar os educandos a pensar (ver) com a (ou a partir da) Sociologia, objetivando por meio da prática docente o despertar de um olhar mais atento às relações e aos fenômenos sociais que o cerca, a fim de minimizar a postura comum de "olhar não vendo" e/ou de explicar os fenômenos a partir de uma perspectiva do senso comum. Por "olhar não vendo" entendemos a banalização do olhar, o olhar despreocupado pela compreensão do que acontece diante dos olhos. "Olhar" aqui é entendido como algo quase natural; trata-se do ato de enxergar que não supera a percepção de senso comum. "Ver" estaria relacionado a uma compreensão sociológica do que está diante dos olhos.

Como destacou Sardelich (2006, p. 204), tem havido em nossa sociedade um crescente interesse pelo visual e isso "tem levado historiadoras/es, antropólogas/ os, sociólogas/os e educadoras/es a discutirem sobre as imagens e a necessidade de uma alfabetização visual", ainda que o despertar da Sociologia para a fotografia tenha sido tardio (FERRO, 2005). Esse artigo propõe justamente discutir essa necessidade, buscando destacar as potencialidades no uso da fotografia como recurso didático no

\footnotetext{
${ }^{1}$ Doutorando em Sociologia pela Universidade de São Paulo (USP). Bolsista do CNPq.
} 
ensino de introdução à Sociologia, mais especificadamente no desenvolvimento da "imaginação sociológica" entre os discentes do Ensino Médio ou Superior que estão tendo seus primeiros contatos com a Sociologia.

Para o trato do uso da fotografia como instrumento de captura das relações e fenômenos sociais, esse artigo baseando-se em diversas colaborações teóricas, destacando-se Pierre Bourdieu (1990), Pierre Bourdieu e Marie-Claire Bourdieu (2006), Roland Barthes (1984; 1990), Mauro Guilherme Pinheiro Koury (1999) e José de Souza Martins (2014). Quanto ao ver que propomos que seja necessário ser desenvolvido pelos educandos, nos apropriamos das colaborações de Zigmunt Bauman e Tim May (2010), de Wright Mills (1975) e Erving Goffman (1999). A proposta apresentada nesse artigo é fruto de reflexões e práticas acumuladas ao longo de dois anos, tendo sido utilizada com sucesso em turmas de terceiro período do curso de graduação em Administração em uma Instituição de Ensino Superior privada localizada na Região Metropolitana da Grande Vitória. Assim, este artigo apresenta uma indicação propositiva acompanhada de uma fundamentação teórica que julgamos capaz de sustentar o uso da fotografia como um recurso didático que auxilie o professor de Sociologia na sua prática docente, sobretudo no desenvolvimento de uma competência: a imaginação sociológica.

O presente artigo está organizado em quatro seções. A primeira trata-se desta breve introdução. A segunda seção destina-se a uma discussão em torno do uso da fotografia na captura de relações e fenômenos sociais. Na terceira seção nos dedicamos em apresentar a fotografia como recurso didático em aulas Sociologia. Esta seção se subdivide em duas partes; na primeira buscamos delimitar o que entendemos por "ver com (a partir da) Sociologia" e a sua importância para o ensino-aprendizagem dessa disciplina; na segunda parte buscamos destacar de que maneira a fotografia pode ser utilizada como recurso didático para ensinar os educandos a ver, capturar e ler as relações e fenômenos sociais a partir de seu uso; em outros termos, como a fotografia pode ser utilizada para despertar o olhar sociológico. Por fim, na quarta seção, apresentamos nossas considerações finais.

\section{A fotografia e a captura das relações e fenômenos sociais}


Os registros fotográficos vêm sendo cada vez mais presentes na vida cotidiana, seja como formas representativas de momentos vividos, de manifestações artísticas ou de discursos imagéticos. Frente a essa presença, a fotografia vem atraindo muitos pesquisadores, tornando-se objeto de estudo em suas mais diversas formas de manifestação, além de instrumento metodológico de pesquisa de campo, sobretudo na Antropologia Visual e na Sociologia da Imagem. No entanto, ainda há muito a ser feito em relação ao seu uso (FERRO, 2005; MARTINS, 2014).

Por muito tempo a imagem foi tomada apenas como ilustração da mensagem textual. "Os sociólogos clássicos confiaram demasiado na palavra", afirmou Ferro (2005) ao discutir como a Sociologia teria se aproximado da imagem. Porém, sobretudo com o desenvolvimento da Antropologia Visual, a imagem passou a ser compreendida como uma linguagem que pode e deve ser utilizada na pesquisa social como auxiliar na descrição das relações sociais e como técnica de captura de elementos efêmeros dos fenômenos sociais como forma de "preservação" de uma cena que pode se perder no tempo e que registrado de forma imagética pode ser melhor reconstituída à posteriori.

O livro "A Câmara Clara", de Roland Barthes, publicado em 1980, é uma referência em se tratando da temática "fotografia". Nessa obra, Barthes (1984 [1980]) apresenta os sujeitos envolvidos com a fotografia. Trata-se do "Operator", o "Spectator" e o "Spectrum". O fotógrafo é o "Operator", o observador das fotos o "Spectator" e o fotografado é o "Spectrum". Nessa obra, destacou Barthes (1990) que a imagem possui uma retórica polissêmica e muitas vezes a união texto-imagem corrobora para que o pesquisador ou o fotógrafo busque evidenciar um determinado significado escolhido, desconsiderando, em certa medida, os demais possíveis. Isso ocorre porque o Operator tem ciência de que o Spectator pode ter sua própria leitura do Spectrum, uma vez que seu olhar é direcionado por sua cultura e interesses existentes no momento da observação/leitura da imagem. Na imagem os signos aparecem de forma simultânea e não sequencial, "por isso suas relações são sintagmáticas e não temporais" (FERRO, 2005, p. 378). A relação imagem-texto foi uma questão analisada por Foucault (1985, p. 25). Para ele,

\footnotetext{
Não que a palavra seja imperfeita e esteja, em face do visível, num déficit que em vão se esforçaria por recuperar. São irredutíveis uma ao outro: por mais que se diga o que se vê, o que se vê não se aloja jamais no que se diz, e por mais que se faça ver o que se está dizendo por imagens, metáforas,
} 
comparações, o lugar onde estas resplandecem não é aquele que os olhos descortinam, mas aquele que as sucessões de sintaxe definem.

Para Gutiérrez (1995) a imagem é mais poderosa do que a palavra ou o texto, uma vez que aquela é capaz de suscitar mais emoções e sensações que as explicações verbais. "A mensagem simbólica da imagem faz com que vários léxicos possam ser mobilizados, ou seja, uma mesma fotografia pode remeter a diferentes leituras realizadas pela mesma pessoa" (CAVEDON, 2005, p. 16). Nos termos de Koury (1999), há mais conotação na fotografia do que denotação, isso por apresentar múltiplas significações. Para Berger (2001 apud FERRO, 2005, p. 379) "existem coisas que as fotografias não podem dizer", mas existem outras "que as fotografias dizem muito melhor do que as palavras".

Ao tratar da leitura de imagens, sob a faceta semiótica, temos as noções de denotação e conotação.

\begin{abstract}
A denotação refere-se ao significado entendido "objetivamente", o que "objetivamente" se vê na imagem, a descrição das situações, figuras, pessoas e ou ações em um espaço e tempo determinado. A conotação refere-se às apreciações do intérprete, aquilo que a imagem sugere e/ou faz pensar o leitor (SARDELICH, 2006, p. 2008).
\end{abstract}

A fotografia traz justamente essas duas noções importantes a serem consideradas; considerando que as conotações não são de apropriação ou interpretação exclusiva (BODART; SILVA, 2014).

Se por um lado, o uso da fotografia nas pesquisas sociais pode propiciar maiores detalhes, sobretudo trazer à tona elementos subjetivos difíceis de serem apresentados de forma textual; por outro, escapa ao Operator (fotógrafo) o controle das significações que este pretendia transmitir. Por isso que Koury (1999, p. 65) afirmou que "a imagem, então, não possui discurso, mas permite discursos nela, sobre ela e através dela. Discursos que se revelam em choques ou em fusões de olhares múltiplos". A fotografia é objetiva como registro de alguma coisa e é subjetiva na forma de produzi-la e de observá-la (GUTIÉRREZ, 1995).

É importante compreender que a fotografia não retrata a essentia do objeto, mas o olhar do fotógrafo e depois do Spectator (fotografado). Igualmente "a fotografia não captura o objeto, mas o olhar que apreende esse objeto e que não é individual, mas construído social e conjunturalmente" (CAVEDON, 2005, p. 16). Sendo o objeto uma 
construção social, é possível que haja uma leitura compartilhada, embora existindo àquelas individualizadas. Nas palavras de Gutiérrez (1995, p. 239), "existirão tantas interpretações quantos os olhares, porém a capacidade unificadora da imagem faz com que se identifiquem entre si aqueles que compartilham uma mesma imagem cultural". Ao pesquisador social que se utiliza da fotografia lhe ocorre a preocupação em capturar os fenômenos sociais, aqueles que possuem sentidos sociais, e que tal captura seja possível de transmitir tais sentidos. E, a essa tarefa a fotografia apresenta grande potencial, sobretudo quando o Spectrum é convidado a "ler" a fotografia e transmitir ao Operator suas percepções da cena capturada, como muitos pesquisadores já vêm fazendo, sobretudo ao optarem pelo estudo fotoetnográfico.

A Fotoetnografia é apresentada por Achutti (1997, p. 14) como sendo um método que consiste "no uso da fotografia como uma narrativa imagética capaz de preservar o dado e convergir para o leitor uma informação cultural a respeito do grupo estudado". Além da Fotoetnografia, outro campo que vem se desenvolvendo no uso da fotografia é a Sociologia da Imagem.

No campo da Sociologia destacam-se duas contribuições importantes para se pensar o papel e o uso da fotografia na produção do conhecimento sociológico; nos referimos àquelas propostas por Bourdieu (2006) e Martins (2014). Enquanto Bourdieu (2006) enfatiza que a fotografia produzida nas práticas cotidianas pelos indivíduos comuns pode ser tomada como elemento de análise das relações e fenômenos sociais (assim como a observação de seus usos sociais), sobretudo para a compreensão das estruturas sociais dos grupos envolvidos, Martins (2014) destaca a utilidade da fotografia para os estudos sociológicos quando na sua produção já houver prévia intencionalidade sócio-estética por parte do sociólogo-fotógrafo. Diríamos que nos termos de Barthes (1990), uma proposta teria sua atenção voltada ao Spectator (a observação e leitura da imagem) e ao Spectrum (da coisa fotografada), enquanto outra, ao Operator (no fotógrafo ou na prática fotográfica). Abas as propostas têm se mostrado de grande utilidade nos estudos de Sociologia.

Acreditamos que se a intenção é extrair elementos para uma posterior explicação sociológica textual ou oral da cena ou do grupo registrado, a proposta de Bourdieu (2006) nos parece bastante promissora, uma vez que nenhum registro do passado pode oferecer um testemunho tão direto como as imagens, sendo mais ricas e precisas que a 
literatura (BERGER, 2007). No entanto, se o propósito é transmitir ao não-sociólogo elementos para uma explicação sociológica por meio de imagens, os apontamentos de Martins nos parece mais frutíferos, isso porque o sociólogo-fotógrafo buscará um registro mais "claro" desses elementos, uma vez que sua proposta é justamente esclarecer, informar, dar acesso a um leitura da cena observada e estruturada racionalmente instantes antes do registro imagético - sobretudo se o objetivo é realizar uma exposição fotográfica cujo objetivo é transmitir um olhar sociológico das cenas registradas, como fez Martins, em 2014, na Universidade de São Paulo (USP), em ocasião do lançamento da segunda edição de "Sociologia da Fotografia e da Imagem". O foco de Martins (2014) está no uso da fotografia como registro de informações sociológicas, enquanto Bourdieu nos parece pensar a fotografia como uma fonte documental que pode ser analisada à posteriori pelo sociólogo.

Propondo o uso da fotografia para treinar um olhar sociológico, o método proposto por Martins nos parece ser mais eficiente. Desta forma, buscamos a seguir destacar de que modo o ato de registrar cenas cotidianas pode ser utilizado como aprendizagem do modo de ver a partir da (com a) Sociologia.

De acordo com Martins (2014, p. 10), no campo da Sociologia há os que acreditam que "um sociólogo (ou um antropólogo) possa fazer imagens propriamente sociológicas, que já contenham em si mesma a descrição e explicação do que foi fotografado ou filmado". Para esse mesmo autor, isso é "uma polarização em relação aos que entendem que a imagem pode ser apenas ilustração do discurso sociológico (ou histórico, ou antropológico) verbal ou escrito" (idem). Para Martins (2014, p.10), o uso da fotografia na Sociologia "nem se situa num desses polos e nem outro". "[...] a fotografia não é apenas documental para ilustrar nem apenas dado para confirmar. Não é nem mesmo tão somente instrumento para pesquisar. Ela é constitutiva da realidade contemporânea e, nesse sentido, é, de certo modo, objeto e também sujeito" (idem, p. 23).

Se por um lado a fotografia não deve ser relegada a "ilustrar" os textos sociológicos, por outro, é necessário a consciência que ela possui suas próprias insuficiências, assim como ocorre as insuficiências do uso das palavras escritas ou faladas (MARTINS, 2014). Não se trata de capturar a realidade, strictu sensu, mas a interpretação do sociólogo-fotógrafo ciente de "que o próprio fotografado, em muitas 
circunstâncias, é um poderoso coadjuvante do ato fotográfico e que, portanto, o real é a forma objetiva de como a ficção subjetiva do fotografado interfere na composição e no dar-se a ver para a concretização do ato fotográfico" (idem, p.15). Outra questão que deve ser considerada é que o leitor da fotografia traz consigo uma bagagem cultural que direciona seu olhar e influencia sua percepção (BODART; SILVA, 2015). No entanto, essa percepção não retira a importância de buscar na fotografia, como destacou Martins (2014, p.33), "a técnica capaz de reter e documentar a dimensão propriamente ontológica do social".

\begin{abstract}
A imagem, assim como o texto, é fruto de uma perspectiva de quem a registra/produz, nunca devendo ser tomada como o real, antes reconhecendo que ambas as descrições/representações "dar-se-ão a ler" a partir "do mundo interpretativo" do leitor (CHARTIEU, 1990 apud BODART, SILVA, 2015).
\end{abstract}

Destaca Martins (2014) que a partir dos anos de 1970 a rigidez da Sociologia amparada em análises tidas como objetivas foi dando lugar a uma Sociologia aberta à subjetividade, ao momento e as formas sociais. De acordo com esse autor, o mundo pósSegunda Guerra Mundial trouxe para o primeiro plano a vida cotidiana e na Sociologia tal plano passa a ter maior relevância, sobretudo após o resgate de obras que se debruçaram sobre as relações sociais do cotidiano, destacando-se o interacionismo simbólico de Herbert Blumer e da dramaturgia social de Erving Goffman. Para Martins, ainda antes de tomar a fotografia como recurso metodológico, a Sociologia do cotidiano passou a trabalhar com descrições sociológicas visuais, como nas obras de Goffman. “Ao expor a teatralidade dos processos sociais referidos ao cotidiano e à sua inevitável espacialidade, a Sociologia passou a usar orientações e procedimentos que, na verdade, são fotográficos" (MARTINS, 2014, p. 35).

\title{
3. A fotografia como recurso didático para desenvolver o olhar sociológico
}

Há uma crescente preocupação em torno do desenvolvimento de recursos didáticos para tornar as aulas mais dinâmicas e atrativas aos educandos, sobretudo no Ensino Básico; no ensino de Sociologia essa preocupação, como era de se esperar, permanece. No entanto, sua intermitência no currículo nacional é um fator contrário ao desenvolvimento de instrumentos didáticos. Só agora há pouco o professor passou a ter 
uma variedade de opções de livros didáticos de Sociologia para o Ensino Médio, por exemplo. A Sociedade Brasileira de Sociologia (SBS), por meio de Congresso Brasileiro de Sociologia, vem, desde 2005, dedicando espaço para discussões em torno do uso de recursos didáticos nas aulas de Sociologia, trata-se do Grupo de Trabalho (GT) Metodologia e Materiais Didáticos. Em 2007 esse GT passou a se chamar "GT Ensino de Sociologia”, mantendo-se como um espaço de discussões em torno da prática docente e os recursos utilizados. O Encontro Nacional de Ensino de Sociologia do Ensino Básico (ENESEB), que está apenas em sua quarta edição, é um esforço na mesma direção. Na sua edição de 2015, foi destinado um GT intitulado "Metodologias e Práticas de Ensino de Ciências Sociais na Educação Básica”, além de cerca de oito oficinas que se propuseram apresentar recursos didáticos para o ensino de Sociologia. Chama a atenção o fato de que duas oficinas objetivaram destacar as possibilidades do uso da fotografia como recurso didático: "Oficina construção do olhar: uso de fotografia para desnaturalizar o contexto escolar" e "Clique sociológico: experimentando a sociologia pela fotografia". No entanto, o número de publicações científicas em periódicos que apresente diferentes possibilidades de recursos didáticos para as aulas de Sociologia, frente à demanda, ainda é bastante tímido e quase sempre os textos são apresentados como relato de experiência docente, entretanto, não indicam os cuidados metodológicos necessários para serem replicados, com os devidos cuidados, em outras realidades. Em se tratando da indicação da apropriação da fotografia como recurso didático em aulas de Sociologia, a escassez é ainda maior, se não inexistente.

Nesse artigo propomos demonstrar que assim como o caderno de campo e outros recursos metodológicos da Sociologia são utilizados no processo-ensino aprendizado, o uso da fotografia pode ser bastante frutífero quando usado adequadamente. Não propomos aqui o uso da fotografia como uma espécie de documento ou registro do passado a ser analisado sociologicamente (o que também é válido), como proposto por Bourdieu como procedimento metodológico, ou tomar o seu uso social como objeto de estudo como fez esse sociólogo, mas se apropriar dela como instrumento metodológico de captura das cenas cotidianas, como propôs Martins (2014) aos sociólogos. Existirão inúmeras possibilidades do uso da fotografia como recurso didático a serem desenvolvidos ou criados. A nossa proposta tenta apenas dar linhas gerais de como seu 
uso pode ser frutífero no ensino de Sociologia, mais especificadamente em levar os educandos a desenvolverem a imaginação sociológica.

O uso da fotografia para a captura de imagens requer conhecimentos técnicos mínimos. No entanto, tais conhecimentos são bastante difundidos e o domínio da técnica de fotografar tem sido facilitado pela tecnologia. As câmeras fotográficas mais usadas são aquelas que oferecem a opção "modo automático", no qual o próprio equipamento faz o controle da velocidade e abertura do obturador, assim como o controle do ISO, do foco e da profundidade de campo a ser captado. No entanto, para uma captura cujo objetivo é retratar um fenômeno social, é necessário a paciência para manter a distância devida do objeto ou cena a ser capturada, assim como a capacidade de perceber a cena e ao mesmo tempo o detalhe (LEAL, 1990).

$\mathrm{O}$ ato de fotografar nos traz uma noção de posse de realidade e, ao mesmo tempo, a certeza da impossibilidade desta posse, de sua fragmentação, e necessidade de reconstrução e processo de revelação desta realidade. A nossa relação com o objeto é sempre uma relação de conhecimento e de poder onde um capta e o outro é captado (LEAL, 1990, p. 16).

Para Koury (1999, p. 66), fotografar "é atribuir sentidos e captar sentidos incorporados no objeto". Nesse sentido, o ato de fotografar pode ser utilizado como um treinamento de um "ver capturador dos sentidos sociais". No caso da Sociologia, em particular, a fotografia pode colaborar para que o educando aprenda a ver com a (a partir da) Sociologia. No entanto, é importante orientar estes que, como destacou Martins (2014), mesmo que nas relações sociais as negociações de significados e o desenrolar dos processos entre sujeitos da situação social observadas sejam inevitavelmente visíveis, não quer dizer que sejam "fotografáveis" e que a fotografia seja um instrumento de captação dos fenômenos e das relações sociais sem erros, muito menos que seja capaz de capturar a realidade strictu sensu.

Warren (2002) destacou a possibilidade de usar a fotografia para a obtenção de sentidos. Esse autor propôs deixar que os informantes operem a máquina fotográfica, fazendo eles mesmos o registro daquilo que julgam importante em sua realidade social, assim o pesquisador passa a ter explicações de tal realidade, o que ele dificilmente conseguiria capturar. Nesse sentido, nota-se que o uso da fotografia para o registro dos fenômenos sociais não demanda ser o Operator um cientista social, o que abre espaço para pensarmos no uso da fotografia por educandos que estão sendo introduzidos nos 
estudos dos fenômenos sociais e, em diálogo com outros atores do processo ensinoaprendizado, desenvolver a imaginação sociológica, sendo guiado para não se limitar a perspectiva do senso comum, ainda que essa possa ser o ponto de partida.

A fotografia vem sendo tomada cada vez mais como objeto de análise sociológica, ainda que seja na Antropologia que historicamente possui maior centralidade como instrumento metodológico ou como feitura e compreensão da expressão possível das relações sociais (FERRO, 2005). Se há um crescente reconhecimento da utilidade desse instrumento para a produção do conhecimento sociológico (idem), acreditamos que devemos tomá-lo também como recurso didático no ensino de Sociologia em seus diversos níveis, sobretudo na sua introdução. Grosso modo, a proposta é conduzir os educandos a uma prática de pesquisa de campo cujo instrumento de coleta de dados seja a fotografia, como propõe Martins (2014) ao profissional da sociologia. Nossa defesa de seu uso na introdução à Sociologia deve-se pela sua acessibilidade e presença constante na vida cotidiana, assim como os propósitos de ensino-aprendizagem de levar os educandos a pensar e ver com (a partir da) Sociologia. Por ver com (a partir da) Sociologia entendemos a tarefa intelectual de observar as cenas cotidianas e ser capaz de compreender as relações sociais que as marcam, assim como aprender a olhar os fenômenos sociais com familiaridade quando exóticos e com estranheza quando familiares; como apresentaremos a seguir.

\section{O uso da fotografia para aprender a ver com a (a partir da) sociologia}

"Aprender a pensar com a Sociologia" é o título, em português, de uma obra produzida por Bauman e May (2010), a qual nos é bastante sugestiva em seus apontamentos em torno do ato de pensar e ver sociologicamente. Outro texto caro a essa questão é a obra “A imaginação Sociológica”, de Mills (1975).

Propomos nessa seção discutir o uso da fotografia para o desenvolvimento de uma "imaginação sociológica" e a importância dessa "habilidade" como ponto de partida em direção a um processo de ensino-aprendizagem significativo. Devido a necessidade de aproximar o educando dos conteúdos abordados nas aulas, o livro "A representação do Eu na Vida Cotidiana”, de Erving Goffman (1975), é indicado para aguçar no aluno a percepção dos detalhes que existem nas relações sociais cotidianas. $\mathrm{O}$ 
fio condutor e estruturante dessa subseção são trechos do poema de Otto Lara Rezende, "Ver vendo".

Há alguns anos, atuando no Ensino Médio, realizei um projeto da escola envolvendo cerca de 100 alunos. Naquela ocasião a proposta de utilizar a fotografia, mais especificamente o ato de fotografar como recurso didático, foi pensado de forma próxima ao que aqui propusemos destacar. No entanto, a falta de um arcabouço teóricometodológico fez com que o resultado não fosse o esperado: ensina o "conteúdo" “imaginação sociológica”. Ao longo de alguns anos lecionando Sociologia no Ensino Médio e depois em cursos superiores de outras áreas, sempre me deparei com o "conteúdo" de introdução à Sociologia, e nele o desafio de explicar o que seria a “imaginação sociológica”. Há cerca de 2 anos, resolvi retomar a proposta de utilizar da fotografia como recurso didático, no entanto com outra perspectiva: a imaginação sociológica não poderia ser entendida como "conteúdo", mas como prática, como uma maneira de "ver" as cenas cotidianas e, assim, a proposta passou objetivar criar condições para que os educandos adquirissem condições para praticar a imaginação sociológica. Em síntese, a "imaginação sociológica" deixou de ser compreendida como "conteúdo" para ser "competência".

Como bem destacaram Fleury e Fleury (2001, p. 187), a noção de competência, quando observada em uma dimensão individual, aparece associada aos verbos "saber agir, mobilizar recursos, integrar saberes múltiplos e complexos, saber aprender, saber engajar-se, assumir responsabilidades, ter visão estratégica". Para esses autores, competência pode ser definida como "um saber agir responsável e reconhecido, que implica mobilizar, integrar, transferir conhecimentos, recursos e habilidades, que agreguem [...] valor social ao indivíduo" (p. 187). Nesse sentido, o papel da imaginação sociológica estaria ligado a uma contribuição ao seu possuidor na direção de dar-lhe maiores condições a atuar e se situar no mundo social com competência.

A partir dessa perspectiva o uso da fotografia passou a fazer mais sentido. Acompanhado dessa mudança buscamos desenvolver um arcabouço teóricometodológico norteador de nossa prática, como propomos apresentar a seguir.

... De tanto ver, a gente banaliza o olhar... Vê não-vendo... Experimente ver pela primeira vez o que você vê todo dia, sem

ver... Parece fácil, mas não é... 
Julgamos importante propiciar as condições necessárias para que o educando desenvolva uma imaginação sociológica (ainda que não venha a ser um sociólogo por formação), pois como destacou Mills (1975, p. 11) "a imaginação sociológica capacita seu possuidor a compreender o cenário histórico mais amplo, em termos de seu significado para a vida intima e para a carreira exterior de numerosos indivíduos". Não é fácil "ver pela primeira vez"; exige-se do observador o exercício prático e constante. Nesse sentido, a "imaginação sociológica" não pode ser reduzida a categoria "conteúdo", mas entendida como "competência" a ser adquirida/desenvolvida. O olhar atento para as configurações compostas pelo cenário, atores, plateia, fachadas, a expressividade, entre outros elementos sociais, é fundamental para a compreensão das relações sociais (GOFFMAN, 1975). A fotografia demanda observação e escolhas e estas dependem de interpretações. Nesse sentido, o seu uso orientado pode vir a possibilitar a atividade prática do ver, induzindo o aluno-fotógrafo a ter mais atenção ao cenário da vida cotidiana que deseja "capturar".

Outra prática que o professor de Sociologia pode propor a desenvolver nos seus educandos por meio do uso do registro fotográfico é a dialética estranhamento/desnaturalização, a qual é capaz de ampliar percepção dos símbolos existentes nas relações sociais da vida cotidiana (CUNHA; RÖWER, 2014).

Da Matta (1978) nos ajuda a pensar o processo de transformar o exótico em familiar e/ou transformar o familiar em exóticos. Para ele, transformar o exótico no familiar significa a "busca de liberdade dos enigmas sociais situados em universos de significação sabidamente incompreendidos pelos meios sociais do seu tempo" (DA MATTA, 1978, p. 4), ou seja, se refere a busca pelo reconhecimento e compreensão do outro. Já transformar o familiar em exóticos significa "estranhar alguma regra social familiar e assim descobrir [...] o exótico no que está petrificado dentro de nós pela reificação e pelos mecanismos de legitimação" (DA MATTA, 1978, p. 5). Como destacaram Cunha e Röwer (2014), o que torna algo familiar ou exótico não é a distância ou a proximidade que produz familiaridade ou exotismo, naturalidade ou estranhamento, mas sua incompreensão ou compreensão. Assim, ao levar os educandos a olharem com mais atenção as cenas cotidianas, estes poderão, via a imaginação sociológica adquirida, ter uma percepção desfamiliarizada, despertando assim o 
interesse pela observação e o desenvolvimento de uma competência importante para seu posicionamento no mundo social.

De acordo com Boris Kossoy (2001), os registros fotográficos representam a visão de mundo do fotógrafo, isso independentemente do assunto proposto. Frente a isso, observar o registro fotográfico dos alunos e indagar-lhes sobre o que "capturaram" pode ser uma forma possível de avaliá-lo e perceber como estes estão enxergando o mundo social e se ainda mantém uma visão centrada no indivíduo, característica do senso comum (BAUMAM; MAY, 2011), ou se consegue perceber as relações complexas que compõe a cena da vida cotidiana, ainda que em um enquadramento escolhido em um recorte de tempo-espaço (GOFFMAN, 1975).

\section{O campo visual da nossa rotina é como um vazio... Você sai todo dia, por exemplo, pela mesma porta.. Se alguém lhe perguntar o que você vê no seu caminho, você não sabe... De tanto ver, você não vê... [...].(Otto Lara Rezende).}

Como bem destacou Sardelich (2006), a visualização é uma característica do mundo contemporâneo, no entanto essa característica não significa, necessariamente, que temos conhecimento do que está à nossa vista. Para esse autor, a riqueza da experiência visual, por um lado, e a precária habilidade para compreender o que é visto, abre uma demanda pelo desenvolvimento da cultura visual como campo de estudo. Acrescentamos a essa afirmação a necessidade inerente à prática docente em buscar ampliar a habilidade dos alunos em "ver o mundo". Utilizamos o termo "ver" em contraposição a "olhar". Este uma prática quase natural, aquela uma prática social, marcada pela compreensão do que se olha. No caso do professor de Sociologia, conduzir os seus educandos a ver a partir da "imaginação sociológica". Como destacou Bauman e May (2010) há uma tendência de as pessoas comuns enxergarem apenas as suas biografias e seu microcosmo de forma isolada, sem contudo compreender as relações existentes entre sua biografia e as demais biografias; isso entendemos por "olhar". "Ver" trata-se de de uma competência social capaz de mobilizar conhecimentos adquiridos para a compreensão de uma dada complexidade (FLEURY; FLEURY, 2001). 
Para Mills (1975), a imaginação sociológica é caracterizada pela percepção entre biografia e história, entre os indivíduos e estrutura. Bauman e May (2010) destacam que o olhar sociológico deve buscar as relações entre nossa biografia e as demais. Nesse sentido, o professor de Sociologia deve criar condições para que o educando tenha tais percepções ao olhar para os acontecimentos e configurações sociais que o cerca, passando do "olhar" para a prática de "ver". Para isso, é necessário despertar a prática do ver os enquadramentos sociais, marcado pelas atuações dos atores que são influenciados pelo cenário a qual estão inseridos. Captar as influências dos cenários e da plateia sobre as representações dos indivíduos (GOFFMAN, 1975) é ampliar o campo visual, é dá "profundidade de campo" e colocar "foco" das relações complexas da vida cotidiana. Nesse sentido, ao apresentar aos alunos a câmera fotográfica é possível realizar analogias que são bastante elucidativas.

A partir de uma compreensão introdutória do domínio do uso de equipamento fotográfico no "modo manual" (função existente em câmeras digitais simples) o alunofotógrafo poderá não só obter melhores resultados estéticos nos seus registros fotográficos, como poderá compreender, em analogia, algumas características do ver sociológico.

Para o uso da câmera fotográfica no "modo manual" é importante conhecer as funções do obturador, do diafragma e do ISO. Grosso modo, o obturador pode ser entendido como uma espécie de cortina localizada dentro do corpo da câmera fotográfica que abre e fecha para o controle da entrada de luz. O obturador é o responsável por proteger o sensor e se abrir rapidamente para deixar a luz passar no momento do clique, do registro fotográfico. O diafragma fica na lente da máquina fotográfica e controla a quantidade de luz que chega ao obturador, deixando a passagem maior ou menor, dependendo de sua abertura; dentre suas funções, destaca a de controlar a profundidade de campo. O ISO é a sensibilidade à luz que o sensor possui. Quando há pouca luz na cena fotografada, ampliando o ISO (a sensibilidade do sensor) conseguimos mais luz e, consequentemente, uma fotografia menos escura e com mais informações.

Em síntese, quanto mais fechado o diafragma da máquina fotográfica, maior será o campo de profundidade da imagem, ou seja, mais nítido ficará o assunto, o elemento que intencionalmente se quer fotografar. No contrário, se o diafragma estiver muito 
aberto apenas um plano da imagem ficará nítido e os demais desfocados, não sendo possível ver todos os elementos da cena. Essas questões técnicas rementem a questões teóricas-metodológicas da Sociologia que podem ser exploradas de formas análogas. Assim, podemos explorar junto ao nosso aluno que em analogia à Sociologia, quanto maior a especialização do sociólogo mais clareza/nitidez terá do objeto em análise e maior capacidade de compreender (ver) os diversos elementos sociais que compõem a cena. No registro fotográfico se o desejo é capturar os movimentos, é necessária paciência em manter o obturador aberto por mais tempo. Na pesquisa sociológica para que sejamos capazes de captar os "movimentos das relações sociais" é necessário um tempo maior de observação. Nesses casos, o trabalho de campo com posse do "caderno de campo" é uma das práticas mais recorrentes. Assim quando na falta de luz na cena a ser fotografada torna-se necessário aumentar a sensibilidade do sensor (ISO), para captar a realidade social, na prática do olhar sociológico, quanto mais obscuras forem as relações sociais, maior será a necessidade de um esforço intelectual para a sua compreensão. Assim, na introdução dos alunos ao uso da fotografia do "modo manual", o docente poderá tomar tais analogias como um ponto de partida interessante para compreender prática do "ver" a realidade social.

[...] O hábito suja os olhos e lhes baixa a voltagem... Mas há sempre o que ver... Gente, coisas, bichos... Evemos?

Não, não vemos... [...].(Otto Lara Rezende).

Nos alerta Mills (1975) que, de maneira geral, a nossa consciência é moldada pela nossa vivência cotidiana; as relações com vizinhos, família e amigos constroem nosso olhar para a realidade, passando à prática do que aqui chamamos de "ver". Raramente conseguimos pautar nossas ações a partir de referências mais amplas, históricas e sociais; as relações entre "homem e sociedade" e "biografia e história" não estão no centro de nossas preocupações habituais, seguimos nos guiando pelo imediato e próximo.

Enquanto o olhar do senso comum, com suas peculiaridades, tira o prazer da observação, isso por ser entendida como corriqueira e banal, “a imaginação sociológica nos permite compreender a história e a biografia e as relações entre ambas, dentro da 
sociedade" (MILLS, 1975, p. 12). Como elas se relacionam de forma dinâmica, sua observação passa a ser novidade. Nesse sentido, é possível levar os educandos a realizar seus registros fotográficos de uma mesma cena cotidiana, porém em momentos diferentes, o que os levarão a compreender o dinamismo da realidade social cotidiana, na qual ainda que o cenário seja o mesmo, os atores, a plateia, as fachadas, as representações tenderão a se manifestar de formas variadas (GOFFMAN, 1975).

Oliveira (2015) destaca a importância de uma "vigilância epistemológica" por parte do professor de Sociologia. Isso porque o aluno possui, a priori, um olhar típico do senso comum (que é uma forma de enxergar o seu mundo social) e cabe ao professor de Sociologia levá-lo a desenvolver um novo olhar; em outros termos, a realizar uma releitura do mundo social a partir de uma orientação teórica-metodológica ofertada pela Sociologia. Nesse processo, o educador deve ser um facilitador e para isso utilizar-se dos recursos necessários, dentre os quais a fotografia é um deles.

A "vigilância epistemológica" destacada por Oliveira (2015) deve ser reforçada em cada ação educativa e, nesse contexto, entendemos que o registro fotográfico deve ser precedido de uma percepção sociológica. Ou seja, será a teoria que nos "dirá" se uma dada cena é propícia para que a fotografia venha possuir conteúdo sociológico (FERRO, 2005). Nesse sentido, não se trata de levar os alunos ao campo (que pode ser o pátio da escola, o entorno desta ou qualquer outro local onde as relações sociais possam ser mais facilmente captadas e "capturadas" pelos alunos) e solicitar que tirem fotos. É necessário ter previamente uma base teórica-metodológica mínima para "ver o que antes não via”. Já dizia Florestan Fernandes que para a Sociologia "o importante, parece, não é o que se 'vê', mas o que se observa com método" (2004, p. 126 apud OLIVEIRA, 2015).

\footnotetext{
Uma criança [como um sociólogo] vê o que um adulto não vê... Tem olhos atentos e limpos para o espetáculo do mundo... O poeta [como um sociólogo] é capaz de ver pela primeira vez o que, de tão visto, ninguém vê... [...]. (Otto Lara Rezende).
}

"No fundo a Fotografia é subversiva, não quando aterroriza, perturba ou mesmo estigmatiza, mas quando é pensativa” (BARTHES, 1984, p. 62). Será pensativa na medida em que despertar o olhar mais atento, a imaginação compreensiva, típica da imaginação sociológica. A partir desse momento terá condições de ver as cenas 
cotidianas que se descortinam diante de nossos alhos a partir de relações complexas que se dão entre atores, plateias, cenários, figurinos, scripts, fachadas, aparências e maneiras (GOFFMAM, 1975).

No processo de avaliação, o docente deverá estar atento ao fato de que ao registrar uma cena o educando o estará fazendo a partir de sua percepção do mundo social, uma vez que "toda imagem encarna um modo de ver. [...] as fotos não são, como se costuma supor, um mero registro mecânico" (BERGER, 2007, p. 6). Os registros dos alunos serão fruto de suas percepções e escolhas, uma vez que ao registrar a cena cotidiana o aluno-fotógrafo realizou escolhas, optando por registrar algumas manifestações do social em detrimento do não registro de uma infinidade de outras possíveis.

Atento a afirmativa de Berger, o professor de Sociologia terá condições de avaliar momentos distintos do processo educativo, buscando comparar registros ao longo da prática do "ver" e do registro do cotidiano por parte do aluno-fotógrafo. Assim poderá acompanhar a evolução do educando rumo a um ver diferente daquele que antes possuía; em direção de uma imaginação sociológica ou simplesmente ver com (a partir da) Sociologia.

É preciso uma tomada de consciência de que a imaginação sociológica é uma contribuição ao seu possuidor na direção de dar-lhe maiores condições para atuar e se colocar no mundo social de forma consciente da complexidade social, e a partir daí ser capaz de enxergar as relações sociais contidas em cada fenômeno social cotidiano, o que consiste em dotar-se de competência que cabe, em grande parte, a um conhecimento sociológico que seja para além de compreensões conceituais.

Lecionar introdução à Sociologia não deve ser, assim nos indica nossa reflexão teórica com base empírica, entendida como transmissão de conteúdo, mas desenvolvimento de uma competência: a "imaginação sociológica".

\section{Considerações finais}

O uso da fotografia na Sociologia vem se expandindo, não só por meio estudos que se debruçam sobre seus usos sociais, como sugeriu Bourdieu (1990), mas também como instrumento metodológico de pesquisa de campo, como indicou Martins (2014). 
Nesse artigo destacamos tais usos para posteriormente apresentar uma proposta com linhas gerais com as quais se poderá coser um instrumento didático para a aula de Sociologia, mais especificamente capaz de corroborar para que o aluno seja possuidor da imaginação sociológica. Diferentemente do que comumente encontramos na literatura, esse paper não se enveredou no relato de experiência docente (o que não significa que esses relatos não sejam importantes, muito pelo contrário), ainda que a proposta apresentada já vem sendo praticada pelo autor desse paper há cerca de dois anos. Antes, apresenta uma proposição acompanhada de uma fundamentação teórica capaz de sustentar o uso da fotografia como um recurso didático que auxilie o professor de Sociologia na sua prática docente, mais especificamente no tema (que, na verdade, é uma competência a ser adquirida) "imaginação sociológica".

A indicação e defesa do uso da fotografia como recurso didático em Sociologia se fundamenta na escassez de recursos desenvolvidos para essa disciplina, isso devido, entre outros fatores, a sua intermitência no Ensino Básico e por ser a fotografia um instrumento presente no cotidiano dos alunos.

Aferimos que o uso da fotografia, acompanhado de uma base teórica mínima, pode se mostrar eficiente em "treinar" o "ver" dos educandos, tornando-os capazes de compreender as cenas da realidade cotidiana marcadas pela complexidade que muitos não veem por não serem dotadas de uma imaginação sociológica ou, nos termos de Bauman e May (2010), por não terem aprendido a pensar com a sociologia. Sem o aprendizado de tal olhar o ensino de Sociologia não se estenderá para além das velhas práticas de memorizações de conceitos e categorias sem sentido para os alunos.

Com base em minha experiência como docente dos níveis de Ensino Médio e Superior, observo que o desafio de desenvolver nos educandos a competência da "imaginação sociológica" varia de acordo com a capacidade/habilidade docente em adequar as ideias de Bauman e May (2010), Mills (1975) e Goffman (1975) ao nível de ensino que atua, uma vez que essas são basilares para o desenvolvimento de tal competência.

A partir de alguns relatos de práticas docentes e de estágios de futuros professores de Sociologia, temos observado que a carência de um embasamento teóricometodológico das práticas docentes que se utilizam de recursos didáticos diversificados tem dificultado aos professores e alunos obterem êxitos no processo de ensino- 
aprendizagem. Pensar o uso de recursos didáticos, como a fotografia, sob um arcabouço teórico-metodológico norteador é cada vez mais urgente; tanto para o processo de ensino-aprendizagem mencionado, quanto para a consolidação da Sociologia no Ensino Médio e sua legitimidade em cursos de graduação de outras áreas. O presente artigo não teve por pretensão apresentar uma "proposta acabada", antes propor algumas linhas gerais de como utilizar o ato de fotografar como um dos recursos possíveis para ensinar os alunos a "ver com a (e a partir da) Sociologia", assim como a possuir uma imaginação sociológica; está tão importante em tempos de individualismo exacerbado que vem direcionando o olhar e as interpretações das cenas cotidianas para o "indivíduo do aqui e agora", ignorando a presença e o papel das redes de relações sociais e do processo histórico na configuração das relações e fenômenos sociais. A "imaginação sociológica" não pode ser compreendida como um mero conteúdo a ser transmitido ao educando, mas como uma competência a ser desenvolvida. Nesse contexto, o ato de fotografar poderá ser uma prática de grande valia e o papel da imaginação sociológica estaria ligada a uma contribuição ao seu possuidor na direção de dar-lhe maiores condições de atuar e se situar no mundo social com competência. Diríamos ainda que a imaginação sociológica deve ser entendida pelo professor de Sociologia como uma competência a ser adquirida por seus educandos.

\section{Referências}

ACHUTTI, L. E. R. Fotoetnografia: um estudo de Antropologia Visual sobre cotidiano, lixo e trabalho. Porto Alegre: Tomo, 1997.

BARTHES, R. A câmara clara. Rio de Janeiro: Nova Fronteira, 1984.

BARTHES, R. O óbvio e o obtuso. Rio de Janeiro: Nova Fronteira, 1990.

BAUMAN, Z; MAY, T. Aprendendo a pensar com a Sociologia. Rio de Janeiro: Zahar, 2010.

BERGER, J. Modos de ver. Barcelona: Gustavo Gili, 2007.

BODART, C. das N; SILVA, R. T. Fabricante e remendador de redes de pesca: um olhar a partir da Etnografia Visual. Iluminuras, Porto Alegre, v. 16, n. 37, 2015, p. 272-296. ago. 2015. 
BOURDIEU, P. et al. Photography: a middle-brow art. Cambridge: Polity Press. 1990. ; BOURDIEU, M.-C. O camponês e a fotografia. Revista de Sociologia Política, Curitiba, n. 26, 2006, p. 31-39. Disponível em:< http://www.scielo.br/pdf/rsocp/n26/a04n26.pdf> Acesso em: 03 nov. 2015.

CAVEDON, N. R. Fotoetnografia: a união da fotografia com a etnografia no descortinamento dos não ditos organizacionais. O\&S, Salvador, v.12, nº35, 2005. Disponível em: < http://www.scielo.br/pdf/osoc/v12n35/a01v12n35.pdf > Acesso em: 08 ago. 2015.

CUNHA, J. L. da; RÖWER, J. E. Ensinar o que não se sabe: estranhar e desnaturalizar em relatos (auto)biográficos. Educação, Cascavel, v. 39, n. 1, 2014, p. 27-38. Disponível em:< http://cascavel.ufsm.br/revistas/ojs2.2.2/index.php/reveducacao/article/view/11340> Acesso em: 11 ago. 2015.

DA MATTA, R. O ofício de etnólogo ou como ter Anthropological Blues. Rio de Janeiro: Boletim do Museu Nacional. Nova Série - Antropologia, $n^{\circ}$ 27, 1978, p. 112. Disponível em: $<$ http://www.museunacional.ufrj.br/ppgas/Boletim_MN/Boletim\%20do\%20Museu $\% 20 \mathrm{~N}$ acional\%2027.pdf> Acesso em: 10 ago. 2015.

FERRO, Lí. Ao encontro da Sociologia Visual. Revista da Faculdade de Letras da Universidade do Porto. Porto, $\mathrm{n}^{\circ}$ 15. 2005.

FLEURY, M. T. L; FLEURY, A. Construindo o conceito de competência. Revista de Administração Contemporânea. Curitiba, Edição Especial, 2001. Disponível em: < http://www.scielo.br/pdf/rac/v5nspe/v5nspea10.pdf> Acessado em: 10 ago. 2015.

FOUCAULT, M. As palavras e as coisas. São Paulo: Martins Fontes, 1985.

GOFFMAN, E. A Representação do Eu na Vida Cotidiana. Petrópolis: Vozes, 1985.

GUTIÉRREZ, M. R. Testimonio y poder de la imagen. In: BAZTÁN, A. Aguirre. Etnografia. Barcelona: Marcombo, 1995.

KOSSOY, B. Fotografia \& História. São Paulo: Ateliê Editorial, 2001.

KOURY, M. G. P. Imagem e narrativa ou, existe um discurso da imagem? Horizontes Antropológicos. Porto Alegre (UFRGS, IFCH, PPGAS). Ano 5, n.12, 1999, p. 59-68.

LEAL, O. F. A leitura social da novela das oito. Petrópolis: Vozes, 1990.

MARTINS, J. de S. Sociologia da Fotografia e da Imagem. 2a ed. São Paulo, Contexto, 2014.

MILLS, W. A Imaginação Sociológica. Rio de Janeiro: Zahar, 1975. 
OLIVEIRA, A. Os desafios teórico-metodológicos do Ensino de Sociologia no Ensino Médio. Perspectiva. Florianópolis, v. 32, n. 3, 2015. Disponível em: < https://periodicos.ufsc.br/index.php/perspectiva/article/view/2175-

795X.2014v32n3p1019>. Acesso em: 14 ago. 2015.

SARDELICH, M. E. Leitura de imagens, cultura visual e prática educativa. Cadernos de Pesquisa. São Paulo, v. 36, n. 128, 2006, p.451-472. Disponível em: $<$ http://www.scielo.br/scielo.php?script $=$ sci arttext\&pid $=\mathrm{S} 0100$ 15742006000200009\&lng=en\&nrm=iso > . Acessado em: 09 ago. 2015.

WARREN, S. Show me how it feels to work here: using photography to research organizational aesthetics. Ephemera. São Francisco, v. 2, n.3, 2002, p. 224-245. Disponível em: < http://www.ephemerajournal.org/sites/default/files/2-3warren.pdf $>$. Acesso em: 15 nov. 2015. 


\title{
Fotografia como recurso didático no ensino de sociologia
}

Resumo: O presente artigo discute as potencialidades do uso da fotografia como recurso didático, especificamente no desenvolvimento de uma competência: a "imaginação sociológica". Destaca, para isso, a importância de uma apropriação teóricametodológico. Argumenta que o ato de fotografar, sob uma perceptiva sociológica, pode proporcionar aos alunos condições de atuar e se situar no mundo social com maior competência.

Palavras-chave: Sociologia; Imaginação Sociológica; Fotografia; Competência

\section{Photography as a teaching resource in the teaching of sociology}

\begin{abstract}
This article discusses the potential of the use of photography as a teaching resource, specifically in the development of a competency: the "sociological imagination". Highlights for this, the importance of theoretical and methodological appropriation. It argues that the act of shooting, under a sociological perceptive, can provide students able to act and be situated in the social world with greater competence.
\end{abstract}

Keywords: Sociology; Sociological Imagination; Photography; Competence

Recebido em: 15 de julho de 2015.

Aceito para publicação em: 04 de novembro de 2015. 